\title{
Passeio pelas lembranças com Augusto de Campos
}

\author{
Walking through the memories with Augusto de Campos
}

\author{
Aurora Bernardini \\ Universidade de São Paulo, São Paulo, São Paulo, Brasil
}

\begin{abstract}
Resumo: $O$ texto trata de relembrar alguns dos momentos mais marcantes das traduções poéticas de Augusto de Campos, a começar pelas francesas de Mallarmé e Válery, onde é dada ênfase particular ao uso que ele faz do ritmo que acompanha o sentido. Passa-se, depois, às traduções russas que focalizam a poesia de Marina Tsvetáieva onde, ao lado da fidelidade tradutória, começase a notar a utilização de um léxico interpretativo com certa distância do original. Nas traduções dos poetas ingleses e americanos, foi focalizado um fragmento de Gertrude Stein e a estratégia de "ler com os ouvidos" de Augusto de Campos, e na tradução do soneto "O dia do juízo" do italiano Agostino Belli, comparada com a tradução do mesmo soneto por Anthony Burgess, foram focalizadas as soluções dadas ao grotesco em termos de criações de "malapropismos" da linguagem popular. Finalmente, num poema de Emily Dickinson, surgiu uma nova estratégia: ao lado da tradução paralela do léxico do poema, o acréscimo de um novo termo (conceito) que não existe literalmente no original, criado para evocar uma certa ambiência, em termos da $A$-tradução proposta por Derrida.
\end{abstract}

Palavras-chave: Tradução poética; Augusto de Campos; Mallarmé; Válery; Tsvetaeva

\begin{abstract}
The text intends to review particular moments of the poetic translations by Augusto de Campos. In the French Mallarmé and Válery translations is stressed the function of rhythm which reinforces the meaning; in the interpretation of Marina Tsvetaeva's poems we start noting the use of certain vocabulary distant from the original, and in one of Gertrude Stein's fragments we learn, according to Campos, how "to read with the ears". In Campos translation of Agostino Belli's sonnet "The last judgement", compared with the translation of the same sonnet by Anthony Burgess, we can see how grotesque is given through the creation of "disproperties"of the popular language. Finally, in Campos' translation of a poem by Emily Dickinson a new strategy is shown: how to introduce a new term (concept) which does not literally exist in the original, which corresponds to the idea of A-translation proposed by Derrida.
\end{abstract}

Keywords: Poetic translation; Augusto de Campos; Mallarmé; Válery; Tsvetaeva 
Da excelente Poesia da recusa (Perspectiva, 2006) que tomo como leme para contornar alguns marcos desse grato passeio, recuo um pouco até o volume Mallarmé de 1974 e relembro uma aula de pós, do saudoso João Alexandre, sobre o tema do cygne do poeta francês (cujo Um Lance de Dados o investe como o "Einstein da poesia" - como dirá Augusto) e sobre as traduções de Válery empreendidas pelo poeta concreto.

Realmente estávamos indecisos sobre a quem dar a palma, se ao célebre original mallarmaico (1885) ou à tradução augustiana, tão fielmente criativa:

$\mathrm{O}$ virgem, o vivaz e o viridente agora Vai-nos dilacerar de um golpe de asa leve Duro lago de olvido a solver sob a neve O transparente azul que nenhum vôo aflora!
Le vierge, le vivace et le bel aujourdd'hui Va-il-nous déchirer avec un coup d'aile ivre Ce lac dur oublié que hante sous le givre Le transparent glacier des vols qui n'ont pas fui!

Quando João Alexandre nos chamou a atenção para a tradução dos advérbios, que Augusto empreende na tradução de um poema de Válery "La dormeuse" (da série Le petit Air, iniciada em 1894), que ele considerava dificilmente superável e que chegou a reproduzir graficamente na pedra:

\section{La dormeuse}

Quels secrets dans son coeur brûle ma jeune amie,

Ame par le doux masque aspirant une fleur?

De quels vains aliments sa naïve chaleur

Fait ce rayonnement d'une femme endormie?

Souffle, songes, silence, invincible accalmie, Tu triomphes, ô paix plus puissante qu'un pleur,

Quand de ce plein sommeil l'onde grave et l'ampleur

Conspirent sur le sein d'une telle ennemie.

Dormeuse, amas doré d'ombres et d'abandons, Ton repos redoutable est chargé de tels dons,

Ô biche avec langueur longue auprès d'une grappe,

Que malgré l'âme absente, occupée aux enfers, Ta forme au ventre pur qu'un bras fluide drape, Veille; ta forme veille, et mes yeux sont ouverts.

P. Válery, 1920
A adormecida

Que segredo incandesces no peito, minha amiga,

Alma por doce máscara aspirando a flor? De que alimentos vãos teu cândido calor Gera essa irradiação: mulher adormecida?

Sopro, sonhos, silêncio, invencível quebranto, Tu triunfas, ó paz mais potente que um pranto,

Quando de um pleno sono a onda grave e estendida

Conspira sobre o seio de tal inimiga.

Dorme, dourada soma: sombras e abandono, De tais dons cumulou-se esse temível sono, Corça languidamente longa além do laço,

Que embora a alma ausente, em luta nos desertos,

Tua forma ao ventre puro, que veste um fluido braço,

Vela. Tua forma vela, e meus olhos: abertos.

Tradução de Augusto de Campos 
"Corça languidamente longa além do laço", dizia um dos versos. Pois bem, esse "languidamente longa" ficou-nos como uma espécie de senha rítmica. Toda vez que se falava de Valéry, aflorava à nossa mente o desenho ondulado e... deliciosamente perverso, não apenas pela flexuosidade de nossa língua, mas pelos milagres da rítmica do Augusto.

Passaram-se muitos anos. Voltamos ao Mallarmé de 1874 que ressurgiu na tradução de seu soneto irregular "Angoisse", sempre por Augusto, tradução essa em que é realçada a recusa dos códigos vigentes da ordem poética mas, dentro das formas exteriores da poesia convencional, com rimas e tudo. E é justamente o impulso dessas formas exteriores que o tradutor preserva quando, novamente, vale-se da recriação, mas percebe-se o surgimento de um léxico pessoal.

A estrofe seguinte, de "Angústia” (Angoisse):

Je ne viens pas ce soir vaincre ton corps, ô bête Em qui vont les pechés d'un peuple, ni creuser Dans tes cheveux impurs une triste tempête Sous $l$ 'incurable ennui que verse mon baiser.
Esta noite eu não vim vencer teu corpo, harpia, Vórtice do pecado, ou cevar no desejo Dos teus cabelos vis um lívido lampejo, Sob o tédio sem fim que o beijo prenuncia.

Vale por uma aula: pode-se, sim, conforme é prática aceita, mudar a pontuação, a interjeição, a pausa, conforme os usos da segunda língua, para não alterar o tão falado "espírito" da primeira, mas o que se nota aqui, em Augusto, já é uma alteração, do léxico, dentro da interpretação da aura temática do original.

\section{Segundo marco: Marina Tsvetáieva}

Tal como o dito atribuído a Dostoiévski, que se perpetuou na Rússia: “ Somos todos filhos do Capote de Gogol" (mas que, na verdade, - escreve-me de Moscou o Professor S. Nekliúdov -, se deve à má tradução para o russo de um artigo do crítico francês E. Bogus, - 1885 - sobre Dostoiévski) todos nós, de uma maneira ou de outra, somos também filhos dessa extraordinária Poesia Russa Moderna de Augusto de Campos, Haroldo de Campos e Boris Schnaiderman, onde pela primeira vez reunidos apareceram, entre outros poetas, Blok, Pasternak, Akhmátova, Mandelstam, Tsvetáieva, Iessiênin, retomados e enriquecidos agora, com novos poemas e ensaios (Cf. os inéditos "Iessiênin, Mais à Esquerda que a Esquerda" e "A Pedra de Mandelstam"), em Poesia da recusa. 
Folheando a primeira edição de 68 de Poesia Russa Moderna, pela Civilização Brasileira, encontro uma anotação feita à margem do poema "À Vida" de Marina Tsvetáieva. Na verdade, mais que uma anotação é uma montagem. Confrontando com meus alunos o original e as admiráveis traduções dos irmãos Campos desse mesmo poema, recordo-me agora que, na época, uma aluna do curso de Russo havia feito uma composição, que lhe pareceu ideal, com os versos dos dois tradutores. Assim rezava, ao lado da tradução de Augusto e de Haroldo, do poema de Tsetáieva “À vida”, a montagem, em cursivo, da primeira estrofe:

\section{Não colherás no meu rosto} sem rugas

A cor, violenta correnteza. És caçador: eu não sou presa. És a perseguição: eu sou a fuga.

Augusto de Campos
Não roubarás minha cor Vermelha, de rio que estua. Sou recusa és caçador. Persegues: eu sou a fuga.

Haroldo de Campos
Àvida

Não roubarás minha cor Vermelha, de rio que estua. És caçador: eu não sou presa És a perseguição: eu sou a fuga. (Montagem)

Na Poesia da recusa - e aqui não resisto ao desejo de comparar nossas duas versões (a de Augusto e a minha, essa última bem rente ao original) de um mesmo poema de Tsvetáieva, de outubro de 1921, o "Louvor de Afrodite" (minha versão segue em itálico).

\footnotetext{
Diante de um rio que é já outro rio

Já os deuses doam menos.

Do largo pórtico sombrio,

Voem, pombas de Vênus!

Mas eu, aqui na areia gélida,

Dia após dia me olho sem saída, Como serpente que olha a velha pele, da Juventude desvestida.
}

\author{
Já os deuses não são tão generosos \\ E nos seus leitos os rios não são os mesmos. \\ Nos vastos portões do ocaso, \\ Voem, pássaros de Vênus! \\ E eu, deitada em areias já frias, \\ Vou para o dia que já não se conta.... \\ Como a serpente olha a velha pele- \\ Cresci para fora de meu tempo.
}

O que se pode notar na tradução de Augusto é a mudança progressiva do léxico que acompanha uma interpretação livre do tema original.

Além de enriquecer o acervo com outros poemas de Marina, ainda não vistos no Brasil ("A carta", "Tentativa de ciúme”, "Encontro de Maiakóvski com Iessiênin no Outro Mundo"), o ensaísta-tradutor traz, pela primeira vez versos da poeta escritos em francês, retirados de Le Gars, (a tradução da própria Tsvetáieva para o francês de seu poema longo Molodiéts “O jovem” ou "O bravo"): 
(O que te

Devo, dí

Vida

Dividida

De vida

Sem som-só sono.

Lar, amor, cor, corpo!

Dorme, dardo! Dorme, flor!)
Mon débit.

Ton dû.

Sitôt dit.

Fond...

\author{
Nul bruit-tout dort: \\ Cour, four, coeur, corps. \\ Dors, dard!Dors, fleur!.
}

que, conforme a recriação de Augusto "preservam o staccato, as quebras de verso, as elipses, as dissonâncias do seu idioleto".

Mais ainda, temos, como fecho final da série o poema-recusa por excelência, "Lágrimas de ira e amor" que Tsvetáieva, em seus últimos dias de França, escreve para a Tchecoslováquia invadida e do qual $\mathrm{T}$. Todorov comentará alguns trechos em francês no livro Vivre dans le feu - confessions (conjunto de cartas e escritos da poeta que saíram pela Martins Fontes com o título de Vivendo sob o fogo)

\author{
Lágrimas de ira e amor! \\ Olhos molhados, quanto! \\ Espanha sem sangue! \\ Tchecoslováquia em pranto! \\ Montanha negra - \\ Toda a luz amputada! \\ É tempo - tempo - tempo \\ De devolver a Deus a entrada! \\ Eu me recuso a ser. \\ No asilo da não-gente \\ Me recuso a viver. \\ Com o lobo regente \\ Me recuso a uivar. \\ Com os tubarões do prado \\ Me recuso a nadar, \\ Dorso dobrado. \\ Ouvidos? \\ Eu desprezo. \\ Meus olhos não têm uso. \\ Ao teu mundo sem senso \\ A resposta é - recuso.
}




\section{Terceiro marco: plêiade dos poetas ingleses e anglo-americanos}

Na plêiade dos poetas ingleses e anglo-americanos apresentados e traduzidos, como os russos, por Augusto de Campos, entre Yeats, Wallace Stevens, Hart Crane, John Donne, Dylan Thomas... detenho-me um pouco mais em Gertrude Stein - como diz Augusto, "a menos assimilada" dos modernistas radicais. Isso por razões em que entram Luci Collins e John Cage. A primeira, pelo fato de que, com sua tese de doutorado na USP sobre Gertrude Stein (de cuja defesa, há alguns anos, tive o prazer de participar), me permitiu conhecer mais profundamente a obra steiniana, especialmente as obras-primas de seus "retratos", e Cage porque, em sua performance vocal por ocasião de seus 80 anos (1992), nos jardins do Metropolitan Museum of Art (a que, por acaso, assisti), me permitiu entendê-la.

De fato - e nesse ponto me cativou sobremaneira a penetração de Augusto, "Cage parece fundir o nonsense steiniano às técnicas colagísticas dos 'Cantos' poundianos. (...) A chance poetry cageana, com suas implicações auditivas (Cage gravou vários de seus textos), me faz refletir sobre um modo de compensar a fragilidade estrutural das redundâncias steinianas.

Talvez os seus textos devam ser encarados mais como libretos do que como obras definitivas, ou definitivamente fixadas no papel. Ou como 'letras' (na acepção de letras de música, mais próximas da conversa e da fala do que da poesia escrita ou estrita). Gertrude afirmava que preferia ouvir com os olhos. Quem sabe não devamos "lê-la" com os “ouvidos". Senão vejamos:

Twenty years after, as much as twenty years after in as much as twenty years after, after twenty years and so on. It is it is it is it is, as if it. Or as if it. More as if it.And if it.And for and as if it.

Vinte anos após, tal qual vinte anos após tal qual vinte anos após tal qual vinte anos após, após vinte anos e tal. É e é e é e é, tal qual se é. Ou se tal se é. Mais se qual se é. Qual mais. Qual mais, se tal se é. E se é. Se tal qual se é.

Fragmento inicial de "Van Ou Vinte Anos Após (Um Segundo Retrato de Carl Van Vechten)", de 1923, na tradução de Augusto de Campos.

\section{Quarto marco: Agostino Belli}

Em 2011 participei da seguinte Mesa redonda: “Augusto de Campos e a tradução-arte" I Encontro de tradutores da Casa Guilherme de Almeida, 1 de outubro de 2011, 16 horas. 
Junto com André Vallias e Lucia Santaella, e eu apresentei os "Sonetos de Giuseppe Agostino Belli (1791-1863) em tradução de Augusto de Campos"

O que logo chamava a atenção, quanto a Belli, é que ele, severo censor do Vaticano deixou, ao morrer, 2279 sonetos em dialeto romanesco "que afrontavam todas as convenções de seu tempo" que ele quis, muitas vezes, destruir mesmo convindo que "lasciva est nobis pagina, vita proba". Nikolai Gógol, que também quis e conseguiu destruir parte de sua obra, ouviu-o declamar alguns dos seus sonetos em Roma, no salão da princesa Volkónskaia e ficou extremamente impressionado como riso que ele suscitava sem mover o menor músculo de seu rosto.

Os sonetos, para quem conhece o romanesco, eram geralmente desbocados. Mas também geniais, a ponto de Anthony Burgess haver-lhe dedicado, em seu livro $A b b A$ AbbA (Little, Brown and Company. Boston-Toronto: 1977), inventando um pseudônimo, nada menos que a tradução para o inglês de 71 de seus sonetos e o haver tido não só como "um dos gênios do cômico", mas até mesmo como inspirador de Joyce. Aqui vai a tradução de Augusto de um trecho do livro de Burgess, em À margem da margem:

\begin{abstract}
James Joyce, o romancista irlandês que trabalhou miseravelmente como bancário em Roma, nos primeiros anos deste século, parece ter lido Belli, cuja vasta sequência de sonetos, apresentando realisticamente a vida cotidiana de uma grande cidade e capital, pode ser vista como uma espécie de proto-Ulisses. Belli pode ser considerado um liame subterrâneo entre a era do romantismo e a do naturalismo. (1989)
\end{abstract}

Augusto de Campos dedicou-lhe um estudo, no livro mencionado $\grave{A}$ margem $d a$ margem (Companhia das Letras. São Paulo: 1989), que termina com este parecer:

'Flashes' fellinianos, diríamos hoje, desses cine-sonetos que extraem do dia a dia o seu ácido ceticismo, filtram o sal da linguagem nos malapropismos da língua popular, para flagrar o sensível e o poético no grotesco e captar o engenho no ingênuo. Salva, por mãos compreensivas, do fogo a que ele censor de si mesmo - a condenara, contra ele próprio, ainda fustiga e instiga. (p. 56)

(1987)

Aqui vai o original de um dos sonetos em romanesco, sua transcrição em prosa para o italiano, a tradução do Augusto de Campos e, para comparação, a tradução de Anthony Burgess: 
«Er giorno der giudizzio

Quattro angioloni co le tromme in bocca Se metteranno uno pe cantone A ssonà: poi co ttanto de vocione Cominceranno a di: "Fora a chi ttocca"

Allora vierà su una filastrocca

De schertri da la terra a ppecorone, Pe ripijà ffigura de perzone

Come purcini attorno de la biocca.

E sta biocca sarà Dio benedetto, Che ne farà du' parte, bianca, e nera: Una pe annà in cantina, una sur tetto.

All'urtimo uscirà 'na sonajera D'angioli, e, come si ss'annassi a letto, Smorzeranno li lumi, e bona sera.»

O dia do juízo

Quatro marm'anjos botarão a boca No trombone, um em cada canto, e então, Com toda a força dos pulmões dirão:

“É hora pessoal. Fora da toca!"

Depois virá chegando a massaroca De esqueletos, da terra, de roldão, Catando os corpos pra reunião, Pintos em torno da galinha choca.

E a galinha será Deus poderoso, Separando a pureza da sujeira: Uns vão pro caldeirão, outros pro gozo,

Por último virá uma fieira

De arcanjos: um a um, belo e formoso, apagarão a luz e "bona sera".

25 novembre 1831
«Il giorno del giudizio

Quattro grandi angeli, con le trombe in bocca, Si disporranno ai quattro angoli dell'universo A suonare: poi con una gran vociona Cominceranno a gridare: "Sotto a chi tocca".

Allora comincerà a venire su una lunga fila Di scheletri da sottoterra, camminando carponi Per riprendere la forma umana

Raggruppandosi come fanno i pulcini con la chioccia

E questa chioccia sarà Dio benedetto Che li dividerà in due parti, buoni e cattivi Questi da sprofondare all'inferno e quelli da mandare in Paradiso

Alla fine verrà una schiera

D'angeli e, come quando si va a dormire,

Spegneranno tutte le luci e buona notte!»

(https://it.wikipedia.org/wiki/Er_giorno_der_giu dizzio. Acesso em 05 set. 2021.

The last judgement

At the round earth's imagined corners let Angels regale us wirh a brass quartet, Capping that concord with a fourfold shout: "Out everybody, everybody out!"

Then skeletons will rattle all about Forming in file, on all fours, tail to snout, Putting on flesh and face until they get, Upright, to where the Judgement Seat is set.

There, the All High, maternal, systematic, Will separate the black souls from the white: That lot there for the cellar, this the attic.

The wing'd musicians now will chime or blare a Brief final tune, then they'll put out the light: Er-phwhoo And so to bed. Owwwwwww.

Bona sera.

\section{Quinto e último marco: $A$-traduzir}

Além da mestria do ritmo, da criação lexical e livre-interpretação do original acrescentase, aqui, uma estratégia augustiana totalmente inesperada: um acréscimo de sentido que - eventualmente - o original escondia. 
Valho-me aqui de um exemplo e de uma explicação aduzidos por Élida Ferreira, na revista Tradterm n. 39 em que apresentado um original de Emily Dickinson e a correspondente tradução augustiana:

48

I hide myself within my flower.

That fading for your Vase,

You, unsuspecting, feel for me -

Almost a loneliness.

(Emily Dickinson, p.124)
Me oculto em minha flor,

Que fana no teu Vaso,

Sem suspeitar, sentes por mim -

Quase tristeza acaso.

(Augusto de Campos, p.125)

Nota-se aqui que, além da tradução relativamente fiel, há o acréscimo de um termo que não existe no original. A introdução do termo "acaso" produz um efeito estético e um efeito de construção sentido que a autora do ensaio chama de "deslizamento" e que eu teria seguido de bom grado, em minhas próprias traduções, caso tivesse lido o texto sobre A-traduzir, que a autora faz remontar a Derrida.

“... seria necessário transformar pela de transformação: uma transformação regulada de uma língua por outra, de um texto por outro" (DERRIDA, 2001, p. 26).

De fato, na minha tradução dos poemas do Doutor Jivago (para a Companhia das Letras), fiquei tentada em abolir os termos "os séculos", abaixo, e substituí-los por "a ventura" que, além de sua função rítmica/rímica, "a ventura" ainda tinha, em comum com "séculos", a ideia espaço-temporal de continuidade incerta.

Faltou-me o desprendimento que teve Augusto de Campos, mas suas lições hão de persistir.

\section{3. СКАЗКА}

Встарь, во время оно,

В сказочном краю

Пробирался конный

Степью да репью.

(...)

Сомкнутые веки.

Выси. Облака.

Воды. Броды. Реки.

Годы и века.
13. conto

Antigamente, naquele tempo,

No país da fantasia,

Um valente cavaleiro

Entre as bardanas corria.

(...)

Cerradas as pálpebras.

As nuvens. A altura.

As águas. Os vaus.

O tempo. Os séculos. [A ventura.] 


\section{Referências}

BURGESS, Anthony. AbbA, AbbA. Boston-Toronto: Little Brown and Company, 1977

CAMPOS, Augusto de. Verso reverso controverso. São Paulo: Perspectiva, 1978.

CAMPOS, Augusto de. Paul Válery: a serpente e o pensar. São Paulo: Editora Brasiliense, 1984.

CAMPOS, Augusto de. À margem da margem. São Paulo: Companhia das letras, 1989.

CAMPOS, Augusto de, CAMPOS, Haroldo de. PIGNATARI, Decio. Mallarmé. São Paulo: Perspectiva, 1974.

CAMPOS, Augusto de, CAMPOS, Haroldo de. SCHNAIDERMAN, Boris. Poesia Russa Moderna. 6 ed. São Paulo: Perspectiva, 2001

CAMPOS, Augusto de. Poesia da recusa. São Paulo: Perspectiva, 2006.

DERRIDA, Jacques. Posições. Trad. De Tomaz Tadeu da Silva. Belo Horizonte: Autêntica. 2001.

DICKINSON, Emily. Não sou ninguém. Introdução e tradução de Augusto de Campos. Campinas: Editora da Unicamp, 2008.

FERREIRA, Élida. Augusto de campos a-traduzir Emily Dickinson. Tradterm, n. 39 v. 2, 2021.

PASTERNAK, Bóris. Doutor Jivago. São Paulo: Companhia das Letras, 2017.

VÁLERY, Paul. Ouvres 1. Paris: Éditions Gallimard, 157.

Recebido em: 17 de setembro de 2021 Aceito em: 01 de dezembro de 2021

Publicado em dezembro de 2021

Aurora Bernardini

E-mail: bernaur2@yahoo.com.br

ORCiD: https://orcid.org/0000-0002-2559-7080 